\title{
Alteration of the phospho- or neutral lipid content and fatty acid composition in Listeria monocytogenes due to acid adaptation mechanisms for hydrochloric, acetic and lactic acids at pH 5.5 or benzoic acid at neutral pH
}

\author{
Sofia K. Mastronicolis • Anita Berberi • Ioannis Diakogiannis • \\ Evanthia Petrova • Irene Kiaki - Triantafillia Baltzi • \\ Polydoros Xenikakis
}

Received: 29 December 2009/Accepted: 29 March 2010/Published online: 9 April 2010

(C) The Author(s) 2010

\begin{abstract}
This study provides a first approach to observe the effects on Listeria monocytogenes of cellular exposure to acid stress at low or neutral $\mathrm{pH}$, notably how phospho- or neutral lipids are involved in this mechanism, besides the fatty acid profile alteration. A thorough investigation of the composition of polar and neutral lipids from L. monocytogenes grown at $\mathrm{pH} 5.5$ in presence of hydrochloric, acetic and lactic acids, or at neutral $\mathrm{pH} 7.3$ in presence of benzoic acid, is described relative to cells grown in acid-free medium. The results showed that only low $\mathrm{pH}$ values enhance the antimicrobial activity of an acid. We suggest that, irrespective of $\mathrm{pH}$, the acid adaptation response will lead to a similar alteration in fatty acid composition [decreasing the ratio of branched chain/saturated straight fatty acids of total lipids], mainly originating from the neutral lipid class of adapted cultures. Acid adaptation in L. monocytogenes was correlated with a decrease in total lipid phosphorus and, with the exception of cells adapted to benzoic acid, this change in the amount of phosphorus reflected a higher content of the neutral lipid class. Upon acetic or benzoic acid stress the lipid phosphorus proportion was analysed in the main
\end{abstract}

S. K. Mastronicolis $(\bowtie) \cdot$ A. Berberi · I. Diakogiannis ·

E. Petrova · I. Kiaki - T. Baltzi · P. Xenikakis

Food Chemistry Laboratory, Department of Chemistry,

University of Athens, Panepistimiopolis Zografou,

15771 Athens, Greece

e-mail: smastro@chem.uoa.gr phospholipids present: cardiolipin, phosphatidylglycerol, phosphoaminolipid and phosphatidylinositol. Interestingly only benzoic acid had a dramatic effect on the relative quantities of these four phospholipids.

\section{Keywords Listeria monocytogenes .}

Fatty acids · Acid adaptation · Neutral lipids and phospholipids - Weak acid food preservative . Hydrochloric acid

\section{Introduction}

The foodborne pathogen Listeria monocytogenes emerged in the late 20th century and has been cause of many outbreaks of listeriosis with high case fatality rates. Listeria survival depends on membrane lipid homeostasis and on its ability to adjust lipid composition to acclimatize to different environments. The first step to understanding the role of the membrane in adaptation is to define in detail the composition of the membrane. Mastronicolis et al. (1996a) isolated phospholipids of L. monocytogenes and reported that four main phospholipids represented $88 \%$ of the total L. monocytogenes polar lipids.

Listeria monocytogenes cells exposed to low temperature (Annous et al. 1997; Mastronicolis et al. 2006), osmotic (Chihib et al. 2003), anaerobic stresses (Jydegaard-Axelsen et al. 2004) and low pH 
stress (Giotis et al. 2007) undergo alterations in membrane fatty acid (FA) profiles. As a component of cellular membranes, FA are essential from a qualitative and a quantitative point of view. In optimal conditions L. monocytogenes is characterised by $>85 \%$ branched chain fatty acids (BCFA; principally anteiso C15:0 [ai-C15:0] and anteiso C17:0 [ai-C17:0]) (Mastronicolis et al. 2005). It appears that membrane modifications differ from those documented in other genera, where exposure to moderately acidic conditions results in increased levels of monounsaturated long-chain FA in the membrane; in Listeria, higher proportions of straight chain fatty acids (SCFA) are incorporated into the membrane (Ryan et al. 2008). The physiological response to mild acidic stress (acid tolerance response, ATR) has the potential to influence the survival of bacteria in acidic environments, sub-optimal to growth (Gahan et al. 1996). Acids inhibit essential molecular reactions by several mechanisms; one of these is by increasing $\mathrm{H}^{+}$concentration, which results in a decrease in internal $\mathrm{pH}\left(\mathrm{pH}_{\mathrm{i}}\right)$ (Brown and Booth 1991). This drop in $\mathrm{pH}_{\mathrm{i}}$ is a major cause of growth inhibition by weak acids (Beales 2004). The antimicrobial effect of weak acids is both $\mathrm{pH}$-dependent and non-pH dependent, although this has been long established to be more active in an acid than in a neutral environment (Eklund 1983; Vasseur et al. 1999).

Inducing resistance to one stress also increases resistance of bacteria to other types of stress. L. monocytogenes cells exposed to sublethal acid stress have increased resistance to heat, ethanol and salt stress (Bayles 2004). Acid adaptation can increase L. monocytogenes resistance to nisin activity (van Schaik et al. 1999). The cross-resistance of acid adapted cells to other stresses has important implications, since foods commonly encounter sublethal acidic treatments during processing (Gandhi and Chikindas 2007). The acid response of cells involves changes in cell physiology. Modifications in fatty acid composition are extensive enough to alter membrane fluidity and permeability, in order to minimise energy expenditure and to optimise growth. Moreover, the surface physicochemical properties of cells that govern biofilm formation, such as hydrophobicity, van der Waals and Lewis acid-base characteristics and electrical properties, in part depend on membrane phospholipid composition and their modulation (Haest et al. 1972; Gianotti et al. 2008; Prokopovich and Perni 2009). L. monocytogenes has a known ability to attach to and survive on surfaces found in food-processing plants (Giovannacci et al. 2000).

In order to determine whether membrane FA adaptation is a specific survival mechanism for L. monocytogenes grown at $\mathrm{pH} 5.5$ with hydrochloric, acetic or lactic acid, (conditions under which L. monocytogenes is acid-sensitive) we examined whether this phenomenon also occurs in the presence of benzoic acid at neutral $\mathrm{pH}$. The aim of the study was to investigate changes in the $L$. monocytogenes phospho- or neutral lipids and their FA profiles, in response to environmental $\mathrm{pH}$, under the influence of various acids in order to provide a better understanding of acid adaptation mechanism in this bacterium.

\section{Materials and methods}

Culture of the organism

An avirulent strain of L. monocytogenes, DP-L1044 (D. Portnoy, University of Pennsylvania), prepared by a transposon insertion (Camilli et al. 1991) in the parent strain (Lm10403S), was grown in Brain Heart Infusion broth (BHI, Difco Laboratories) at $30^{\circ} \mathrm{C}$ $(24 \mathrm{~h})$. A $10 \mathrm{ml}$ aliquot of this was then inoculated into 11 of $\mathrm{BHI}$ broth, which was then incubated at $30^{\circ} \mathrm{C}\left(\mathrm{Lm}_{\text {control }}\right)$ until early stationary phase $\left(\mathrm{OD}_{600}=0.8 ; 8 \mathrm{~h}\right)$. Four aliquots $(10 \mathrm{ml})$ of the same stock were each inoculated into $11 \mathrm{BHI}$ that were, respectively, adjusted to $\mathrm{pH}_{\text {initial }} 5.5$ with (i) $\mathrm{HCl}\left(\mathrm{Lm}_{\mathrm{HCl}}\right)$, (ii) L-lactic acid (Fluka) $\left(\mathrm{Lm}_{\mathrm{LA}}\right)$, or (iii) acetic acid (Merck) $\left(\mathrm{Lm}_{\mathrm{AA}}\right)$. Another $10 \mathrm{ml}$ aliquot was used to inoculate $11 \mathrm{BHI}$ with the addition of $1.00 \mathrm{~g}$ benzoic acid (Merck, pa) $\left(\mathrm{Lm}_{\mathrm{BA}}\right) \mathrm{pH}_{\text {initial }}$ 7.3. All the above cultures were incubated at $30^{\circ} \mathrm{C}$ until early stationary phase.

Extraction of total lipids (TL) and isolation of polar (PL) and neutral (NL) lipid classes

Cells pelleted by centrifugation were washed twice in phosphate buffer (pH 7.0). TL were extracted (Folch et al. 1957) and separated into PL and NL lipids by solid-phase extraction (SPE) as previously described (Berger et al. 1992; Mastronicolis et al. 2005). 
Methanolysis of lipids and gas chromatography (GC)

Each culture lipid sample (TL, PL and NL) was converted to methyl esters (FAME) as previously described (Vance and Sweely 1967; Mastronicolis et al. 2006). FAME were separated by using a Shimadzu gas chromatograph with a split/splitless injector, flame ionisation detector, capillary column DB-5ms (Phenyl Arylene polymer virtually equivalent to $5 \%$-phenylmethylpolysiloxane; $30 \mathrm{~m}$ by $0.251 \mathrm{~mm}, 0.25 \mu \mathrm{m}$ film thickness, Cat No. 1225532, Serial No. US3270652 H, J\&W Scientific). Carrier gas (He) flow was $44 \mathrm{ml} / \mathrm{min}$. The injector and detector were maintained at 250 and $280^{\circ} \mathrm{C}$, respectively. The oven temperature was ramped from 90 to $170^{\circ} \mathrm{C}\left(70^{\circ} \mathrm{C} / \mathrm{min}\right)$ and from 170 to $210^{\circ} \mathrm{C}$ $\left(5^{\circ} \mathrm{C} / \mathrm{min}\right)$. The initial and final holding times were 1 and 2 min, respectively. Two standard mixtures were used: bacterial FAME (CP Matreya, Inc.) and Marine oil FAME (Restek Corp.).

Identification and quantification of membrane phospholipids by thin-layer chromatography (TLC) and phosphorus analysis

TL phosphorus analysis was performed as previously described (Long and Staples 1961). Chloroform/ methanol/acetic acid/water (50/25/6/2, vol/vol/vol/ vol) was used for one dimensional thin-layer chromatography (1D-TLC; silica gel G60 aluminum chromatoplate [Merck 1.05554], $0.25 \mathrm{~mm}$ thick, $10 \times 10 \mathrm{~cm}$ ). Spots were visualised using iodine, ninhydrin and phosphomolybdenum blue (Dittmer and Lester 1964). The standards cardiolipin (CL), phosphatidylglycerol (PG), phosphatidylinositol (PI), phosphatidylcholine (PC) and lyso-phosphatidylethanolamine (L-PE) were purchased from Sigma Chemical Co. Individual phospholipids (PhL) bands (cells $\mathrm{Lm}_{\mathrm{BA}}$ or $\mathrm{Lm}_{\mathrm{AA}}$ ) were quantified after 1D-TLC fractionation of each PL sample $(10 \mu \mathrm{g}$ applied phosphorus): each iodine-visualised band $(n=4)$ was scraped into a digestion tube and the total phosphorus content was determined as previously published (Kariotoglou and Mastronicolis 1998).

Statistical analysis

Results were evaluated by analysis of variance (ANOVA) (Downie and Heath 1974; Zar 1999).
$T$-test for unpaired observations was tested at a confidence level of $95 \%$.

\section{Results}

Lipid fractionation and lipid class composition of acid adapted L. monocytogenes

Growth of L. monocytogenes in BHI medium to early stationary phase, in the presence of four different acids, was determined by measuring absorbance (OD) at $600 \mathrm{~nm}$. The obtained $\mathrm{OD}_{600}$ values: $\mathrm{Lm}_{\mathrm{HCl}}=0.271$ $\pm 0.013,24 \mathrm{~h}(n=5) ; \mathrm{Lm}_{\mathrm{LA}}=0.083 \pm 0.018,168 \mathrm{~h}$ $(n=4) ; \mathrm{Lm}_{\mathrm{AA}}=0.210 \pm 0.031,72 \mathrm{~h}(n=12)$; and $\mathrm{Lm}_{\mathrm{BA}}=0.682 \pm 0.013,10 \mathrm{~h}(n=9)$ provided information on the sensitivity of cells in each culture adapted to different conditions. Cells grown at neutral $\mathrm{pH}$, in presence of $1 \mathrm{~g} / \mathrm{l}$ benzoic acid, displayed little difference from normal cells $\mathrm{Lm}_{\text {control }}(\mathrm{OD}=0.816 \pm$ $0.032,10 \mathrm{~h}, n=8$ ).

TL were extracted from adapted and non-adapted cells of L. monocytogenes at early stationary phase, and fractionated into PL and NL classes. NL from each culture were quantified by weight and shown in Table 1 . The growth of $L$. monocytogenes in the presence of hydrochloric, acetic, or lactic acid at $\mathrm{pH}$ 5.5 , caused a substantial increase $(31.9,49.3$, and $41.7 \%$, respectively, $P<0.01$ ) of $\mathrm{NL}$ percentage compared to $\mathrm{Lm}_{\text {control }}$ cells. Interestingly, the growth of $L$. monocytogenes in the presence of benzoic acid caused a slight decrease $(6 \%, P<0.05)$ in the NL percentage. The lipid phosphorus content of each TL sample is shown in Table 1.

Listeria monocytogenes growth in the presence of three different acids at $\mathrm{pH} 5.5$, or in presence of benzoic acid at neutral $\mathrm{pH}$, was accompanied by a significant reduction $(P<0.01)$ in lipid phosphorus compared to $\mathrm{Lm}_{\text {control }}$ cells as follows: $\mathrm{Lm}_{\mathrm{BA}} 33.9 \%$, $\mathrm{Lm}_{\mathrm{HCl}} 33.6 \%, \mathrm{Lm}_{\mathrm{LA}} 67.3 \%$ and $\mathrm{Lm}_{\mathrm{AA}} 51.3 \%$.

\section{Effect of acids on L. monocytogenes}

TL, PL and NL fatty acid composition

TL FA profiles of discrete adapted $L$. monocytogenes cells were similar and dominated by four major FA (in order: ai-C15:0, ai-C17:0, C16:0 and C18:0), which totalled $69.5,69.3,60.0$ and $69.4 \%$ for $\mathrm{Lm}_{\mathrm{BC}}$, $\mathrm{Lm}_{\mathrm{HCl}}, \mathrm{Lm}_{\mathrm{AA}}$ and $\mathrm{Lm}_{\mathrm{LA}}$, respectively (Fig. 1). In 
Table $1 \%$ neutral lipids (NL), the ratio of neutral to polar lipids (NL/PL) and \% phosphorus content of each L. monocytogenes total lipid sample extracted from cells grown in optimum conditions $\left(\mathrm{Lm}_{\text {control }}\right)$ or grown in the presence either

\begin{tabular}{lccccc}
\hline & $\mathrm{Lm}_{\text {control }}$ & $\mathrm{Lm}_{\mathrm{BA}}$ & $\mathrm{Lm}_{\mathrm{HCl}}$ & $\mathrm{Lm}_{\mathrm{AA}}$ & $\mathrm{Lm}_{\mathrm{LA}}$ \\
\hline NL $(\%$ w/w of TL) & $36.7 \pm 1.2$ & $34.5 \pm 0.3^{\mathrm{a}}$ & $48.4 \pm 2.3^{\mathrm{b}}$ & $54.8 \pm 0.6^{\mathrm{b}}$ & $52.0 \pm 1.4^{\mathrm{b}}$ \\
NL/PL (w/w) & 0.58 & 0.53 & 0.94 & 1.21 & 1.08 \\
Phosphorus (\% of TL) & $3.39 \pm 0.16$ & $2.34 \pm 0.39^{\mathrm{c}}$ & $2.25 \pm 0.22^{\mathrm{d}}$ & $1.64 \pm 0.44^{\mathrm{c}}$ & $1.11 \pm 0.01^{\mathrm{e}}$ \\
\hline
\end{tabular}

Values are mean \pm standard deviation of at least three replicates performed on each total lipid sample/cell culture

a Value statistically ( $t$-test) decreased compared to $\mathrm{Lm}_{\text {control }}, P<0.05$, for (degrees of freedom) df $=4$

b Values statistically ( $t$-test) increased compared to $\mathrm{Lm}_{\text {control }}$, for $P<0.01$, df $=3$

c Values statistically ( $t$-test) decreased compared to $\mathrm{Lm}_{\text {control }}$, for $P<0.01$, df $=14$

d Value statistically ( $t$-test) decreased compared to $\mathrm{Lm}_{\text {control }}$, for $P<0.01$, $\mathrm{df}=10$

e Value statistically ( $t$-test) decreased compared to $\mathrm{Lm}_{\text {control }}$, for $P<0.01$, $\mathrm{df}=9$

contrast, ai-C15:0 and ai-17:0 alone represented $69.1 \%$ of the $\mathrm{Lm}_{\text {control }}$ TL FA, as observed previously (Mastronicolis et al. 2006). Upon acid stress, the proportion of saturated SCFA (C16:0, C18:0) in the $L$. monocytogenes TL increased at the expense of BCFA (ai-C15:0 and ai-C17:0). For each batch of acid adapted cells, the ratio of total BCFA to total saturated SCFA ( $\sum \mathrm{BCFA} / \sum$ saturated SCFA) of their TL, PL and NL FA profiles compared to $\mathrm{Lm}_{\text {control }}$ is shown in Fig. 2. It is worth noting that the NL FA ratio in adapted cells shows a similar large ( $\times 8$ fold) decrease in relation to the ratio of the $\mathrm{Lm}_{\text {control }}$ cells, while the PL FA ratio shows a smaller decrease (averaging $\times 1.7$ fold). These findings appear to indicate that the mechanism for L. monocytogenes growth under the influence of acids, regardless of acid type, involves a strong increase of $\sum$ saturated SCFA at the expense of $\sum$ BCFA as reflected in the FA composition of the TL due to NL FA. Total unsaturated FA (including C16:1 and C18:1) increased from $1.7 \%$ in the TL FA of $\mathrm{Lm}_{\text {control }}$ cells to 7.9, 8.3, 14.5 and $15.4 \%$ in $\mathrm{Lm}_{\mathrm{BA}}$, $\mathrm{Lm}_{\mathrm{HCl}}, \mathrm{Lm}_{\mathrm{AA}}$ and $\mathrm{Lm}_{\mathrm{LA}}$ cells, respectively. This increase is due mainly to an increase in NL FA.

Effect of benzoic or acetic acid

in L. monocytogenes phospholipid composition

$\mathrm{Lm}_{\mathrm{BA}}$ and $\mathrm{Lm}_{\mathrm{AA}}$ PL samples, separated by 1D-TLC, contained four major phosphocomponents (CL, PG, PhAL, PI) similar to the pattern previously reported (Mastronicolis et al. 1996b, 2008). A new phosphocomponent (designated as A) was observed in both acid adapted cells, and co-chromatographed close to a phosphatidylcholine (PC) standard (Fig. 3). Table 2 shows the lipid phosphorus distribution of each lipid component.

The quantitative composition of the main phospholipids from $\mathrm{Lm}_{\mathrm{BA}}$ cells diverged strongly $(P<0.01)$ from that of $\mathrm{Lm}_{\text {control }}$ cells. When CL, $\mathrm{PG}$ and PI were combined to give the total anionic phospholipids, the value amounted to $53.1 \pm 3.2 \%$ for $\mathrm{Lm}_{\mathrm{BA}}$ and $75.7 \pm 2.2 \%$ for $\mathrm{Lm}_{\text {control }}$ cells.

Unlike $\mathrm{Lm}_{\mathrm{BA}}$ cells, the percentage of the phospholipid species from $\mathrm{Lm}_{\mathrm{AA}}$ cells did not differ greatly from the $\mathrm{Lm}_{\text {control }}$. Specifically the data indicated a slight but significant $(P<0.01)$ decrease of CL and a major decrease $(P<0.01)$ in PG content compared to $\mathrm{Lm}_{\text {control }}$ cells. For the remaining two varieties of phospholipid (PI, PhAL) there appeared to be no statistically significant change.

\section{Discussion}

This study is the first approach to undertake an observation of the involvement of phospho- or neutral lipids in the mechanism of L. monocytogenes cellular adaptation to exposure to acid stress at low or neutral $\mathrm{pH}$, besides their FA profile alteration. Hydrochloric acid will be dissociated whereas acetic $\left(\mathrm{p} K_{\mathrm{a}}=4.74\right)$ and lactic acid $\left(\mathrm{p} K_{\mathrm{a}}=3.79\right)$ will be undissociated at $\mathrm{pH}$ 5.5. The latter form of both acids is membrane permeable and thus allows acetic and lactic acid to enter the microbial cell. Benzoic acid $\left(\mathrm{p} K_{\mathrm{a}}=4.19\right)$ at $\mathrm{pH} 7.3$ will be in its dissociated form (benzoic anion) 


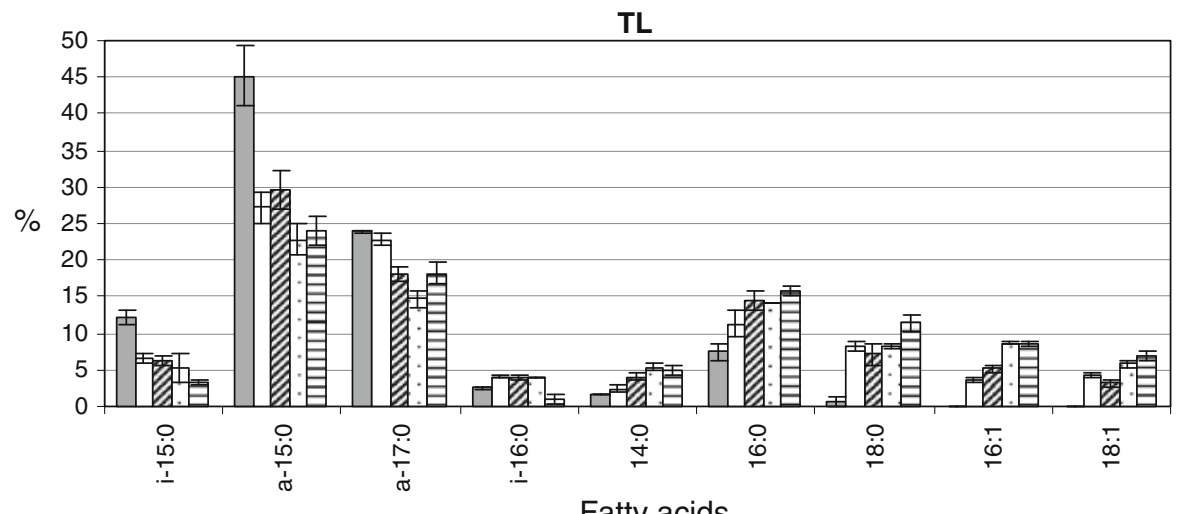

Fatty acids
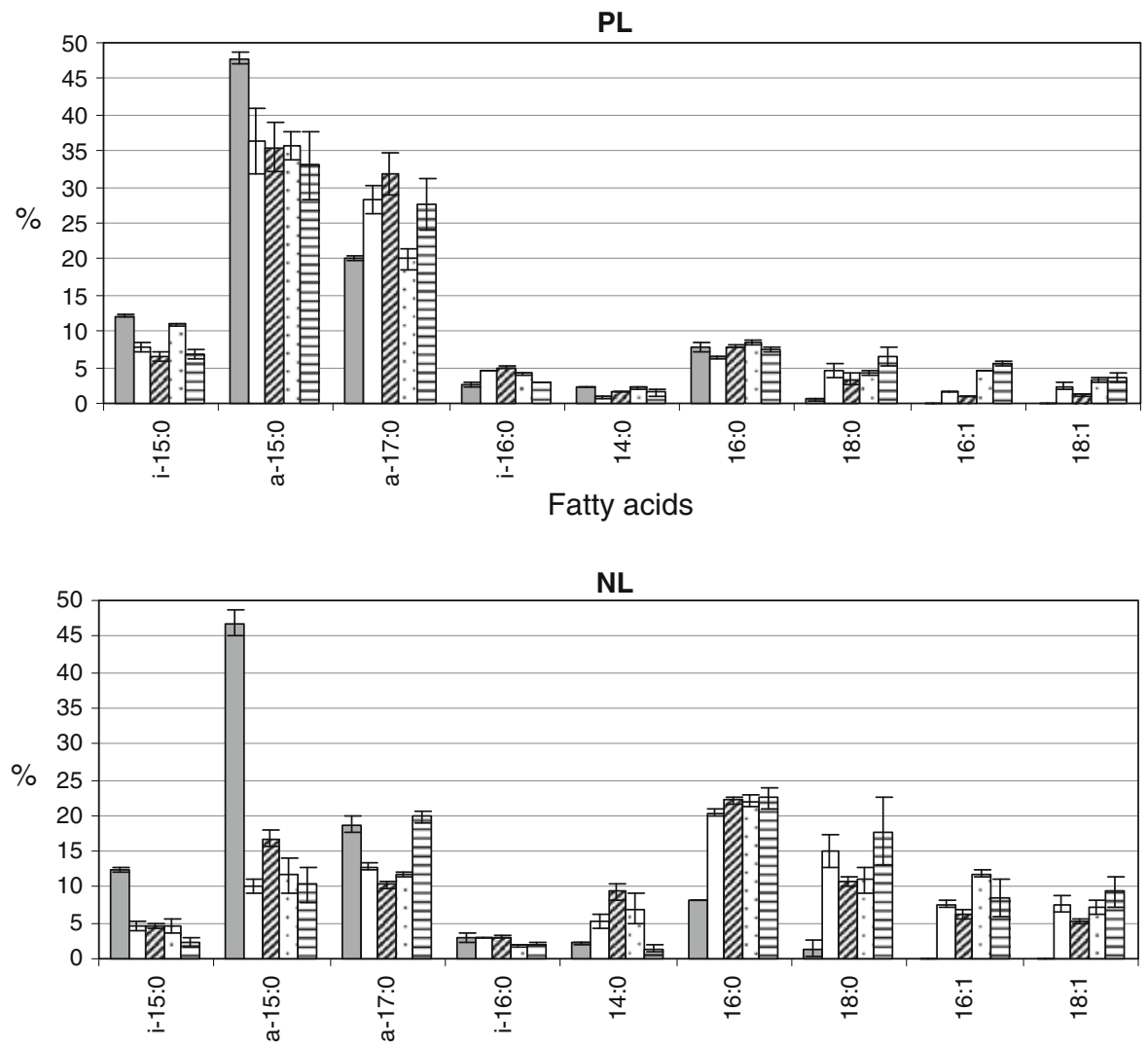

Fatty acids

\section{$\square$ Lmcontrol $\square \mathrm{LmBA} \quad \square \mathrm{LmHCl} \square \mathrm{LmAA} \boxminus \mathrm{LmLA}$}

Fig. 1 Mean concentration (and standard deviation) of fatty acids of (i) total lipids, (ii) polar lipids and (iii) neutral lipids in Listeria monocytogenes before $\left(\mathrm{Lm}_{\text {control }}\right)$ and after acid stress exposure a at $\mathrm{pH} 5.5$ by $\mathrm{HCl}\left(\mathrm{Lm}_{\mathrm{HCl}}\right)$, acetic acid $\left(\mathrm{Lm}_{\mathrm{AA}}\right)$ or

and showed a lower antimicrobial effect on L. monocytogenes. The adaptation mechanism of L. monocytogenes in the presence of acidic stress at
L-lactic acid $\left(\mathrm{Lm}_{\mathrm{LA}}\right)$ and $\mathbf{b}$ at $\mathrm{pH} 7.3$ by benzoic acid $\left(\mathrm{Lm}_{\mathrm{BA}}\right)$. Individual fatty acids comprising $0.1-2.2 \%$ (C14:1, C17:0, C18:2 and C20:0), with the exception of iso C17:0 which amounted to $1.7-4.8 \%$, were ignored

pH 5.5 (enhanced antimicrobial activity) caused: (i) a substantial increase of $\sum$ saturated SCFA at the expense of $\sum B C F A$. This increase is due mainly to 


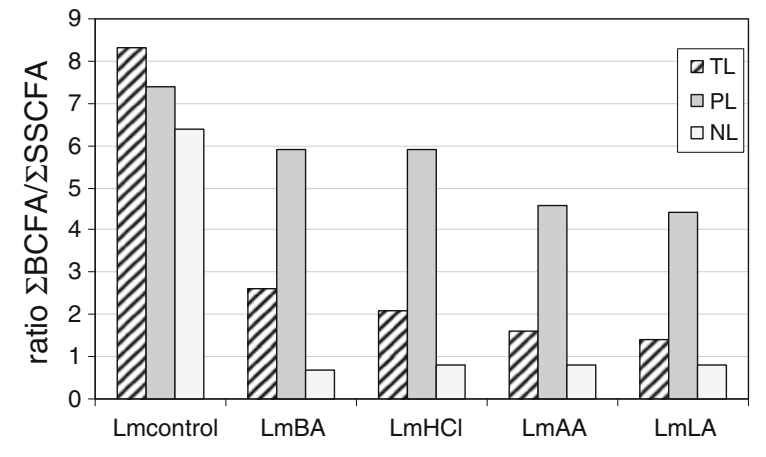

Fig. 2 Ratio of total branched chain fatty acids, BCFA, to total saturated straight chain fatty acids, SSCFA ( $\sum \mathrm{BCFA} /$ $\sum$ SSCFA) of total, polar and neutral lipid FA profiles of cells grown in the presence either of benzoic acid (1 g/l, $\mathrm{pH} 7.3)$ $\left(\mathrm{Lm}_{\mathrm{BA}}\right)$ or at $\mathrm{pH} 5.5$ with hydrochloric $\left(\mathrm{Lm}_{\mathrm{HCl}}\right)$, or acetic acid $\left(\mathrm{Lm}_{\mathrm{AA}}\right)$ or L-lactic acid $\left(\mathrm{Lm}_{\mathrm{LA}}\right)$

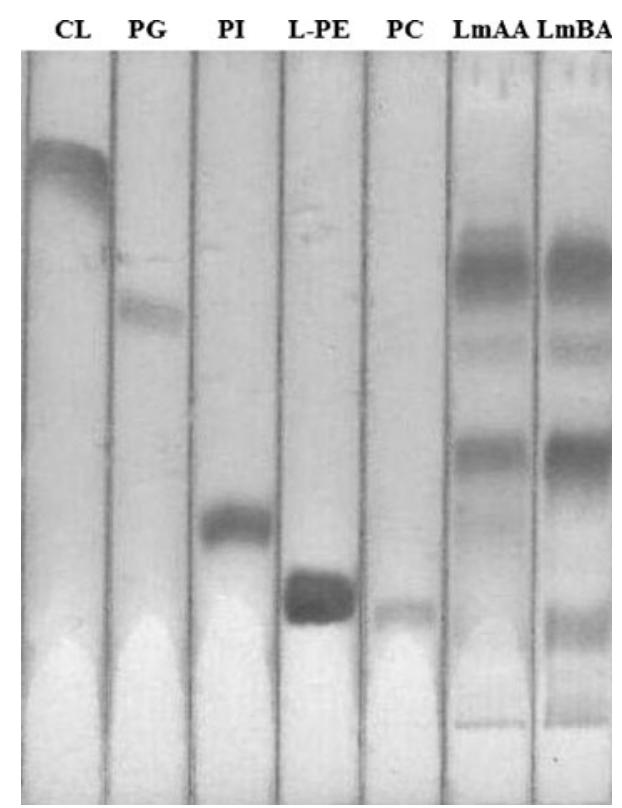

Fig. 3 Thin-layer chromatography separation of individual L. monocytogenes phospholipids derived from cells grown in presence of acetic $\mathrm{Lm}_{\mathrm{AA}}$ or benzoic acid $\mathrm{Lm}_{\mathrm{BA}}$ (6th and 7 th zone, respectively, from the left). The diagram shows these standards from the left to right: $C L$ cardiolipin, $P G$ phosphatidylglycerol, PI phosphatidylinositol, $L-P E$ lyso-phosphatidylethanolamine and $P C$ phosphatidylcholine. The plate was developed using the solvent system chloroform/methanol/ acetic acid/water [50/25/6/2, $\mathrm{vol} / \mathrm{vol} / \mathrm{vol} / \mathrm{vol}]$. Visualisation: after spraying with molybdenum blue reagent. L. monocytogenes cells contained, from top to bottom: CL, PG, PhAL (phosphoaminolipid), PI, and phosphocomponent A an increase in NL FA. (ii) A substantial increase of the percentage of NL, calculated from the increased mass value among TL. Such lipid changes might play a protective role when cells are subjected to (acidic) stress by decreasing the membrane fluidity. It is worth mentioning that the growth of L. monocytogenes in the presence of benzoic acid at neutral $\mathrm{pH}$ caused: (i) a similar alteration in the membrane FA as reported for low $\mathrm{pH}$. (ii) No alteration in the percentage of NL contents, while instead, the relative quantities of phospholipids were dramatically affected by neutralisation of the negative head group charges. Such lipid changes also promote a decrease in membrane fluidity.

Effect of acids on lipid-phosphorus amount and NL content changes

Our data indicated that the acid adaptation response of L. monocytogenes caused a significant decrease in TL phosphorus of each culture (Table 1). In cells grown at low $\mathrm{pH}$ the decrease in phosphorus reflects a higher content of NL, while in cells grown in the presence of benzoic acid at neutral $\mathrm{pH}$, this may reflect a higher content of non-phospholipid components (in the PL class), such as glyco- or aminolipids as indicated by ninhydrin on 1D-TLC. Moreover the lipid phosphorus content of PL from each culture after separation by SPE was also analysed and only in low $\mathrm{pH}$ adapted cells was the PL phosphorus content lower than that of $\mathrm{Lm}_{\text {control }}$ cells (unpublished data). These data reflect the NL accumulation in cells grown at low $\mathrm{pH}$. A similar mechanism was found for cold $\left(5^{\circ} \mathrm{C}\right)$ adapted cells in previous studies (Mastronicolis et al. 2006). Furthermore, other authors (Phan-Thanh and Mahouin 1999; Gandhi and Chikindas 2007) reported that the protein GroEL showed increased synthesis during the growth of L. monocytogenes at low temperatures and was also induced under acid stress. Reduction in the content of phospholipids has also been utilised by L. monocytogenes and other bacteria in response to different environmental stresses such as antibiotics (membrane disrupting peptide) in Pseudomonas aeruginosa (Conrad and Galano 1989) or bacteriocins in L. monocytogenes (Ming and Daeschel 1995) or ethambutol in Mycobacterium tuberculosis (Sareen and Khuller 1990). 
Links between alterations in FA and acid treatment

Alterations in the FA profile may alter membrane permeability and fluidity, which in turn may contribute to acid tolerance. Our data show that, irrespective of $\mathrm{pH}$, the acid adaptation response will lead to a similar alteration in FA composition, mainly in the NL class of adapted cultures. Changes in the FA profile of newly synthesized NL class were also observed in cold $\left(5^{\circ} \mathrm{C}\right)$ adapted L. monocytogenes from our previous studies (Mastronicolis et al. 1998, 2006). The increased percentage in the proportion of C16:0 and C18:0 saturated SCFA (high-melting point FA) was maintained in all the acid adapted cultures. Such modifications are known to decrease membrane fluidity (Russell 1989). The higher proportion of total cis-monounsaturated fatty acids may reflect the induction of adaptive mechanisms in acid adapted L. monocytogenes cells to counteract reduced membrane fluidity, resulting from the increase of saturated SCFA and the reduction of BCFA.

Other authors have reported that exposure of bacteria to moderately acidic conditions results in the incorporation of higher SCFA proportion into their membrane (van Schaik et al. 1999; Fozo and Quivey 2004; Giotis et al. 2007). van Schaik et al. (1999) and Giotis et al. (2007) examined whole cell FA extracts of acid adapted L. monocytogenes and observed only subtle alterations in FA composition.
An increase in saturated SCFA and decrease in BCFA was also observed in Aeromonas spp. (Chihib et al. 2005) and Bacillus subtilis (Lopez et al. 2006) subjected to high $\mathrm{NaCl}$ concentrations. An increase in C16:0 and C18:0 SCFA (Mazzotta and Montville 1997; Naghmouchi et al. 2007) and in the ratio of unsaturated to saturated acyl-chain species of phosphatidylglycerol (Vadyvaloo et al. 2002) was also observed for bacteriocin resistant L. monocytogenes.

The mechanism behind these adaptive responses seemed to be non-specific as similar changes were observed not only under acid stress but also under osmotic stress or in presence of various of bacteriocins.

The effect of benzoic or acetic acid on L. monocytogenes phospholipid composition

Until now there has been no previous reports of the type of phospholipid subspecies present in $\mathrm{Lm}_{\mathrm{BA}}$ or $\mathrm{Lm}_{\mathrm{AA}}$ cells. Interestingly the relative quantity of the four phospholipids CL, PG, PhAL and PI was dramatically affected by benzoic acid (Table 2; Fig. 3). A decrease was observed in the net negative charge of the lipid bilayer of cells. Related data were reported by other authors (Crandall and Montville 1998) for a decrease of total anionic (CL + PG) and an increase of the zwitterionic phosphatidylethanolamine in the resistance to nisin. Additionally neutralisation of the negative head group charges may

Table 2 Separation $^{\mathrm{a}}$ and composition (\% of lipid $\left.\mathrm{P}^{\mathrm{b}}\right)$ of L. monocytogenes phospholipids, grown in optimal conditions cultures, $\mathrm{Lm}_{\text {control }}$ and grown either in the presence of benzoic acid $(1 \mathrm{~g} / \mathrm{l}, \mathrm{pH} 7.28), \mathrm{Lm}_{\mathrm{BA}}$, or of acetic acid $(\mathrm{pH} 5.5) \mathrm{Lm}_{\mathrm{AA}}$

\begin{tabular}{lclr}
\hline Phospholipids & Lm $_{\text {control }}$ & Lm $_{\text {BA }}$ & Lm $_{\text {AA }}$ \\
\hline CL & $48.7 \pm 1.0$ & $29.3 \pm 1.9^{\mathrm{c}}(39.8 \%$ decrease $)$ & $55.4 \pm 3.6^{\mathrm{c}}\left(13.8^{2}\right.$ increase $)$ \\
PG & $18.1 \pm 0.4$ & $11.3 \pm 2.8^{\mathrm{c}}(37.6 \%$ decrease $)$ & $6.7 \pm 1.2^{\mathrm{c}}(63.0 \%$ decrease $)$ \\
PhAL & $19.9 \pm 1.6$ & $28.4 \pm 4.7^{\mathrm{c}}(42.7$ increase $)$ & $19.6 \pm 0.3$ \\
PI & $9.1 \pm 1.8$ & $12.5 \pm 3.9^{\mathrm{d}}(37.4 \%$ increase $)$ & $9.4 \pm 0.8$ \\
Unidentified phospholipid A & - & $18.5 \pm 2.9$ & $8.8 \pm 2.0$ \\
Anionic phospholipids $(\mathrm{CL}+\mathrm{PG}+\mathrm{PI})$ & $75.7 \pm 2.2$ & $53.1 \pm 3.2^{\mathrm{e}}(29.9 \%$ decrease $)$ & $71.6 \pm 2.2^{\mathrm{c}}(5.4 \%$ decrease $)$ \\
\hline
\end{tabular}

The $\%$ difference from $\mathrm{Lm}_{\text {control }}$ is shown in parenthesis

$C L$ cardiolipin, $P G$ phospatidyloglycerol, $P h A L$ phosphoaminolipids, $P I$ phosphatidylinositol

a Phospholipid sample $(10 \mu \mathrm{g}$ phosphorus) fractionated on $10 \times 10 \mathrm{~cm}$ silica gel plates

b Values are mean \pm standard deviation of four replicate phosphorus determinations performed on each lipid band

c Values statistically ( $t$-test) decreased compared to $\mathrm{Lm}_{\text {control }}, P<0.01$, for (degrees of freedom) $\mathrm{df}=12$

d Value statistically ( $t$-test) increased compared to $\mathrm{Lm}_{\text {control }}$, for $P<0.01$, df $=9$

e Value statistically ( $t$-test) increased compared to $\mathrm{Lm}_{\text {control }}$, for $P<0.01$, df $=13$ 
induce a condensation of these phospholipids resulting in a more rigid membrane.

Unlike $\mathrm{Lm}_{\mathrm{BA}}$ the relative quantity of four phospholipids of L. monocytogenes was not dramatically affected in response to acetic acid at low $\mathrm{pH}$.

Other authors (Brown and Booth 1991) reported that an increase in synthesis of aminophospholipids was observed in Staphylococcus aureus during incubation at low $\mathrm{pH}$. Such changes provide the membrane surface with a net positive charge, which may act as a barrier to protons. Furthermore, the synthesis of lysyl-PG has been implicated in resistance against cationic antimicrobial peptides (CAMPs) (Peschel et al. 2001). The synthesis of aminoacylated PG derivatives has been described in several microorganisms. Recently there has been fresh interest in these processes. Klein et al. (2009) found that approximately $0.5 \%$ alanyl-PG content in the membrane composition is sufficient to significantly increase the acidic resistance of $P$. aeruginosa. Toke (2005) reported that the effects of $\mathrm{pH}$ and CAMP resistance are linked. This means that 'tightening' the cell membrane against protons may also render the membrane structure more resistant to CAMPs, to the beta-lactam cefsulodin, but also to additional compounds like $\mathrm{Cr}^{3+}$ ions or sodium lactate (Klein et al. 2009). Additionally, Lopez et al. (2006) investigated the importance of anionic phospholipid content (CL and PG) in the osmotic adaptation and in the membrane structure of B. subtilis. Since changes in the lipid headgroup region of lipid bilayers could lead to modifications in the structure of transmembrane alpha-helices of proteins and as a result, changes in the packing of these helices, it is important to maintain the presence of charged lipids in the bilayer (Lopez et al. 2006).

It has become clear in recent years that bacteria in nature do not prevalently exist in free floating cells but as biofilms attached to surfaces (Costerton 1995; Kolter and Losick 1998). Moreover some microbiologically produced, surface active compounds such as lipids and polysaccharides may influence the interactions of bacterial cells with interfaces (Chamberlain 1992). The increased amount of long chain FA, the accumulation of neutral lipids and the changes in polar head groups of phospholipids observed in our work will affect the physicochemical surface properties of cells. Gianotti et al. (2008) reported dramatic differences between the FA composition of adhered cells of two L. monocytogenes strains (acid adaptive and non-adaptive). It is reasonable to presume that a major proportion of straight FAs is required for the interaction of phospholipids, or their specific loci, with the cell surface proteins that mediate the contact of the cell envelopes with abiotic surfaces (Gianotti et al. 2008). Moreover quorum-sensing allows bacterial cells to collaborate in a way that benefits an entire biofilm population (Baysse et al. 2005; Tarver 2009). Interestingly other authors (Baysse et al. 2005) have shown that the quorum-sensing system of $P$. aeruginosa can also be activated by nutritional stress, independently of cell density, and therefore may be part of a more general adaptive response to stressful environmental conditions.

\section{Conclusions}

Our data points to a role for an acid adaptation response of L. monocytogenes, irrespective of $\mathrm{pH}$, in triggering a significant increase of straight chain FA. This increase is reflected mainly in the NL class FA of acid adapted cells. Additionally our results showed that only low $\mathrm{pH}$ enhances the antimicrobial activity of an acid and the mechanism behind this adaptation response includes NL accumulation in the cells. The nature of the newly-synthesised neutral lipids remained to be determined. Benzoic acid has a slight antimicrobial activity and the percentage of NL and PL remained unchanged, but the relative quantities of four phospholipid subspecies were dramatically affected, while these alterations were not observed in acetic acid adapted cells. Such changes in the lipid profile of the plasma membrane alter membrane permeability and fluidity, which may in turn contribute to tolerance, decreasing the ability of weak acid preservatives to pass through the membrane and thus conferring protection.

The above observations shed further light on how L. monocytogenes is able to adapt its physiology to allow growth in acidic environments. FA biosynthesis is co-ordinately regulated with NL synthesis and growth, as part of the bacterial response to a changing environment and offers unique sites for selective inhibition to combat microbial infection (chemotherapeutic agents). Understanding microbial stress response mechanisms will improve the effective use of preservative factors, help manipulate the survival 
and growth of foodborne microorganisms, and exert microbial control at these points.

Acknowledgments This research was supported in part by the Special Research Account of the National and Kapodistrian University of Athens under project no. 70/4/3338.

Open Access This article is distributed under the terms of the Creative Commons Attribution Noncommercial License which permits any noncommercial use, distribution, and reproduction in any medium, provided the original author(s) and source are credited.

\section{References}

Annous BA, Becker LA, Bayles DO, Labeda DP, Wilkinson BJ (1997) Critical role of anteiso- $C_{15.0}$ fatty acid in the growth of Listeria monocytogenes at low temperatures. Appl Environ Microbiol 63:3887-3894

Bayles DO (2004) Changes in heat resistance resulting from $\mathrm{pH}$ and nutritional shifts of acid-adapted and non-acidadapted Listeria monocytogenes Scott A. J Food Protect 67:316-321

Baysse C, Cullinane M, Denervaud V, Burrowes E, Dow MJ, Morrissey JP, Tam L, Trevors JT, O'Gara F (2005) Modulation of quorum sensing in Pseudomonas aeruginosa through alteration of membrane properties. Microbiology 151:2529-2542

Beales N (2004) Adaptation of microorganisms to cold temperatures, weak acid preservatives, low $\mathrm{pH}$, and osmotic stress: a review. Compr Rev Food Sci Food Saf 3:1-20

Berger A, Gershwin EM, German JB (1992) Effects of various dietary fats on cardiolipin acyl composition during ontogeny of mice. Lipids 27:605-612

Brown MH, Booth IR (1991) Acidulants and low pH. In: Russell NJ, Gould GW (eds) Food preservatives. Blackie, Glasgow, pp 22-43

Camilli A, Goldfine H, Portnoy DA (1991) L. monocytogenes mutants lacking phosphatidylinositol specific phospholipase $\mathrm{C}$ are avirulent. J Exp Med 173:751-754

Chamberlain AHL (1992) The role of adsorbed layers in bacterial adhesion. In: Melo LF, Bott TR, Fletcher M, Capdeville B (eds) Biofilms-science and technology. Kluwer, Dordrecht, pp 59-67

Chihib NE, Ribeiro da Silva M, Delattre G, Laroche M, Federighi M (2003) Different cellular fatty acid pattern behaviours of two strains of Listeria monocytogenes Scott $A$ and CNL 895807 under different temperature and salinity conditions. FEMS Microbiol Lett 218:155-160

Chihib NE, Tierny Y, Mary P, Hornez JP (2005) Adaptational changes in cellular fatty acid branching and unsaturation of Aeromonas species as a response to growth temperature and salinity. Int J Food Microbiol 102:113-119

Conrad RS, Galano C (1989) Fatty acid alterations and polymyxin B binding by lipopolysaccharides from
Pseudomonas aeruginosa adapted to polymyxin B resistance. Antimicrob Agents Chemother 33:1724-1728

Costerton JW (1995) Overview of microbial biofilms. J Ind Microbiol 15:137-140

Crandall AD, Montville TJ (1998) Nisin resistance in Listeria monocytogenes ATCC 700302 is a complex phenotype. Appl Environ Microbiol 64:231-237

Dittmer JC, Lester RL (1964) A simple specific spray for the detection of phospholipids on thin-layer chromatography. J Lipid Res 5:126-127

Downie NM, Heath RW (1974) In: Harper International (eds) Basic statistical methods. Harper \& Row, New York

Eklund T (1983) The antimicrobial effect of dissociated and undissociated sorbic acid at different $\mathrm{pH}$ levels. J Appl Bacteriol 54:383-389

Folch J, Lees M, Stanley-Sloane GH (1957) A simple method for the isolation and purification of total-lipids from animal tissues. J Biol Chem 226:497-509

Fozo EM, Quivey RG Jr (2004) Shifts in the membrane fatty acid profile of Streptococcus mutans enhance survival in acidic environments. Appl Environ Microbiol 70:929-936

Gahan CGM, O’Driscoll B, Hill C (1996) Acid adaptation of Listeria monocytogenes can enhance survival in acidic foods and during milk fermentation. Appl Environ Microbiol 62:3128-3132

Gandhi M, Chikindas ML (2007) Listeria: a foodborne pathogen that knows how to survive. Int J Food Microbiol 113:1-15

Gianotti A, Serrazzaneti D, Kamdem SS, Guerzoni ME (2008) Involvement of cell fatty acid and lipid metabolism in adhesion mechanism of Listeria monocytogenes. Int $\mathrm{J}$ Food Microbiol 123:9-17

Giotis ES, McDowell DA, Blair IS, Wilkinson BI (2007) Role of branched chain fatty acid in $\mathrm{pH}$ stress tolerance in Listeria monocytogenes. Appl Environ Microbiol 73:9971001

Giovannacci I, Ermel G, Salvat G, Vendeuvre JL, BellonFontaine MN (2000) Physicochemical surface properties of five Listeria monocytogenes strains from a pork-processing environment in relation to serotypes, genotypes and growth temperature. J Appl Microbiol 88:992-1000

Haest CWM, de Gier J, op den Kamp JAF, Bartels P, van Deenen LLM (1972) Changes in permeability of Staphylococcus aureus and derived liposomes with varying lipid composition. Biochim Biophys Acta 255:720-733

Jydegaard-Axelsen AM, Hoiby PE, Holmstrom K, Russell N, Krochel S (2004) $\mathrm{CO}_{2}$ and anaerobiosis-induced changes in physiology and gene expression of different Listeria monocytogenes strains. Appl Environ Microbiol 70:41114117

Kariotoglou DM, Mastronicolis SK (1998) Phosphonolipids in the mussel Mytilus galloprovincialis. Z Naturforsch 53c:888-896

Klein S, Lorenzo C, Hoffmann S, Walther JM, Storbeck S, Piekarski T, Tindall BJ, Wray V, Nimtz M, Moser J (2009) Adaptation of Pseudomonas aeruginosa to various conditions includes tRNA-dependent formation of alanylphosphatidylglycerol. Mol Microbiol 71:551-565

Kolter R, Losick R (1998) One for all and all for one. Science 280:226-227 
Long C, Staples DA (1961) Chromatographic separation of brain lipids. Cerebroside and sulphatide. Biochem J 78:179-185

Lopez CS, Alice AF, Heras H, Rivas EA, Sanchez-Rivas C (2006) Role of anionic phospholipids in the adaptation of Bacillus subtilis to high salinity. Microbiology 152:605-616

Mastronicolis S, German JB, Smith GM (1996a) Diversity of the polar lipids of the food-borne pathogen Listeria monocytogenes. Lipids 31:635-640

Mastronicolis SK, German JB, Smith GM (1996b) Isolation and fatty acid analysis of neutral and polar lipids of the food bacterium Listeria monocytogenes. Food Chem 57:451-456

Mastronicolis SK, German JB, Megoulas N, Petrou E, Foka P, Smith GM (1998) Influence of cold shock on the fattyacid composition of different lipid classes of the foodborne pathogen Listeria monocytogenes. Food Microbiol 15:299-306

Mastronicolis SK, Arvanitis N, Karaliota A, Litos C, Stavroulakis G, Moustaka H, Tsakirakis A, Heropoulos G (2005) Cold dependence of fatty acid profile of different lipid structures of Listeria monocytogenes. Food Microbiol 22:213-219

Mastronicolis SK, Boura A, Karaliota A, Magiatis P, Arvanitis N, Litos C, Tsakirakis A, Paraskevas P, Moustaka H, Heropoulos G (2006) Effect of cold temperature on the composition of different lipid classes of foodborne pathogen Listeria monocytogenes: focus on neutral lipids. Food Microbiol 23:183-194

Mastronicolis SK, Arvanitis N, Karaliota A, Magiatis P, Heropoulos G, Litos C, Moustaka H, Tsakirakis A, Paramera E, Papastavrou P (2008) Coordinated regulation of coldinduced changes in fatty acids with cardiolipin and phosphatidylglycerol composition among phospholipid species for the food pathogen Listeria monocytogenes. Appl Environ Microbiol 74:4543-4549

Mazzotta AS, Montville TJ (1997) Nisin induces changes in membrane fatty acid composition of Listeria monocytogenes nisin-resistant strains at $10^{\circ} \mathrm{C}$ and $30^{\circ} \mathrm{C}$. J Appl Microbiol 82:32-38

Ming X, Daeschel MA (1995) Correlation of cellular phospholipid content with nisin resistance of Listeria monocytogenes Scott A. J Food Protect 58:416-420

Naghmouchi K, Kheadr E, Lacroix C, Fliss I (2007) Class I/Class IIa bacteriocin cross-resistance phenomenon in Listeria monocytogenes. Food Microbiol 24:718-727
Peschel A, Jack RW, Otto M et al (2001) Staphylococcus aureus resistance to human defensins and evasion of neutrophil killing via the novel virulence factor $\mathrm{MprF}$ is based on modification of membrane lipids with L-lysine. J Exp Med 193:1067-1076

Phan-Thanh L, Mahouin F (1999) A proteomic approach to study the acid response in Listeria monocytogenes. Electrophoresis 20:2214-2224

Prokopovich P, Perni S (2009) An investigation of microbial adhesion to natural and synthetic polysaccharide-based films and its relationship with the surface energy components. J Mater Sci 20:195-202

Russell NJ (1989) Functions of lipids: structural roles and membrane functions. In: Ratledge C, Wilkinson SG (eds) Microbial lipids. Academic Press, London, pp 279-365

Ryan S, Hill C, Gahan CGM (2008) Acid stress responses in Listeria monocytogenes. Adv Appl Microbiol 65:67-91

Sareen M, Khuller GK (1990) Cell wall and membrane changes associated with ethambutol resistance in Mycobacterium tuberculosis H37 Ra. Antimicrob Agents Chemother 34:1773-1776

Tarver T (2009) Biofilms: a threat to food safety. Food Technol 63:46-52

Toke O (2005) Antimicrobial peptides: new candidates in the fight against bacterial infections. Biopolymers 80:717735

Vadyvaloo V, Hastings JW, van der Merwe MJ, Rautenbach M (2002) Membranes of class IIa bacteriocin-resistant Listeria monocytogenes cells contain increased levels of desaturated and short-acyl-chain phosphatidylglycerols. Appl Environ Microbiol 68:5223-5230

van Schaik W, Gahan CG, Hill C (1999) Acid-adapted Listeria monocytogenes displays enhanced tolerance against the lantibiotics nisin and lacticin 3147. J Food Protect 62:536-539

Vance DE, Sweely CC (1967) Quantitative determination of neutral glycosyl ceramides in human blood. J Lipid Res 8:621-630

Vasseur C, Baverel L, Hebraud M, Labadie J (1999) Effect of osmotic, alkaline, acid or thermal stresses on the growth and inhibition of Listeria monocytogenes. J Appl Microbiol 86:469-476

Zar JH (1999) Biostatistical analysis. Prentice-Hall, Upper Saddle River 